Derecho \& Realidad

Núm. 23 • I semestre de 2014

Facultad de Derecho y Ciencias Sociales, UPTC

ISSN: 1692-3936

\title{
Argumentación jurídica y principios constitucionales: su incidencia en el derecho privado
}

\author{
Legal argumentation and constitutional principles: \\ their impact on private law
}

Mario Fernando Muñoz Agredo*

Resumen

El presente trabajo tiene por finalidad mostrar cómo el fenómeno de la constitucionalización ha cobijado todo cuanto le ha sido posible, reflejando no solo su capacidad para influir en la forma de entender el derecho, sino además cómo incluso ha abarcado terrenos que tradicionalmente se consideraban ajenos a la esfera de lo público en cualquier manifestación, como quiera que correspondían a la órbita de lo estrictamente privado, refiriéndose exactamente al ejercicio de la autonomía de la voluntad y dentro de esta, específicamente a la formación, celebración, ejecución y liquidación de los contratos.

Inicia precisando los conceptos de argumentación jurídica y neoconstitucionalismo, luego indica cómo se establece una relación necesaria entre los mismos y menciona los diferentes grados de constitucionalización del derecho. Se observa de qué manera la neoconstitucionalización y la argumentación jurídica, en el caso colombiano, han generado un estado de activismo judicial que ha pretendido abarcar todos los campos posibles en el ejercicio del derecho

* Profesor de tiempo completo de la Universidad de Nariño, especialista en Derecho Financiero de la Universidad del Rosario, especialista en Derecho Constitucional de la Universidad Nacional de Colombia y especialista en Argumentación jurídica de la Universidad de Alicante (España). 
incluso el derecho de los contratos. Así que, frente a lo anterior, no es posible dejar de referirse al fracaso del activismo judicial en otras latitudes y cómo dicho fracaso se podría repetir en Colombia, aunque aquí se ha generado una falsa expectativa sobre dicho activismo en la esfera jurídica colombiana.

\section{Palabras clave}

Neoconstitucionalizacion, argumentación jurídica, constitucionalizaciòn del derecho, ejercicio del derecho.

\section{Abstract \\ This paper is intended to show how the phenomenon of constitutionalization has sheltered all that has been possible, reflecting not only its ability to influence the way we understand the law, but also covered the orbit of the strictly private, referring exactly to the exercise of autonomy and within that, specifically formation, holding, execution and settlement of contracts. \\ It starts defining the concepts of legal argumentation and neoconstitutionalism, then indicates how to establish a necessary connection between them and mentions the different degrees of constitutionalization of law. It is regarded as the neo-constitucionalization and legal arguments, in the case of Colombia, have generated a state of judicial activism, which was intended to cover all possible fields in the practice of law including the law of contracts. Thus it is impossible to look at all this and not relate to the failure of judicial activism in other places and how this failure could be repeated in Colombia and how it has created a false expectation of such activism in the legal field in Colombia.}

\section{Key words}

Neoconstitucionalization, legal argument, constitutionalization of the right, exercise of the right. 


\section{Argumentación jurídica y neoconstitucionalismo. Conceptos}

\subsection{Argumentación jurídica}

Podríamos decir que la argumentación es una de las labores que generalmente desarrollamos los abogados en todos los campos del derecho en el que nos desempeñemos. La actividad del abogado se desarrolla siempre desde dos perspectivas i) el conocimiento de la ley, y ii) la argumentación (Bonorino \& Peña, 2003, p. 5). La argumentación o al menos la argumentación jurídica, supone un aspecto técnico del desempeño profesional del abogado, luego sería válido advertir que hablar de argumentación jurídica es hablar de técnica jurídica o si se quiere de razonamiento jurídico.

Sin embargo, debe hacerse claridad que el concepto de "argumentación jurídica", no solo se refiere a la argumentación judicial, pues esta última es solo una de las caras que puede mostrar la argumentación jurídica. El campo que abarca el concepto es en realidad más amplio y si bien es cierto que entratándose del debate judicial, este termina con la sentencia, la cual por supuesto debe ser argumentada, esta se presenta ya como el producto de las argumentaciones de las partes, así entonces la argumentación judicial se observa como "un ejercicio de evaluación de los argumentos que anteceden a la construcción de la sentencia” (Marrero, 2006, p.65). Juan Antonio García Amado, recordaba, haciendo la diferencia entre discrecionalidad y arbitrariedad, que cuando un juez no da razón ninguna de su fallo, o lo sustenta con elementos metajurídicos (El conferenciante hablaba de revelaciones divinas), incurría en arbitrariedad mayor que la de no haber fallado (García, 2006), esta afirmación, puede a su vez verse complementada con una similar de Wróblewski (citado por García, 1999, p. 139) según la cual "la exigencia de justificación significa que las decisiones en cuestión no son ni evidentes ni arbitrarias", pues, según García Amado, lo evidente no necesita justificación y lo arbitrario prescinde de ella (García, 1999, p.139).

Decíamos entonces que la argumentación jurídica se presenta como la parte técnica de la labor del abogado, esa técnica o ese razonamiento, no puede encontrarse desprovisto de fines hacía los cuales se dirige, pues generalmente se parte de construir argumentos, entendidos estos como encadenamientos de enunciados a partir de los cuales se llega a una decisión (Atienza Rodríguez, 2006:12), lo que en una estructura lógica permitiría ser observado como la construcción de unas premisas para arribar a una conclusión; empleando las palabras de Weston (2005:11), podríamos decir que argumentar es "dar un conjunto de razones o de pruebas en apoyo de una conclusión”. Pero, pese a lo anterior debemos advertir que no todo razonamiento jurídico se traduce necesariamente en lógica, pues hoy en día también es dable hablar de argumentos dialécticos, retóricos, tópicos, etc. 


\subsection{Neoconstitucionalismo}

Ahora bien, sobre el Neoconstitucionalismo, Prieto Sanchís (2007, p. 93 y ss.) ha manifestado que este concepto, entendido también como constitucionalismo contemporáneo o constitucionalismo a secas, se constituye como una expresión referida a una nueva cultura jurídica en la cual, si he entendido bien al autor, el Estado de derecho se nutre de valores y principios de naturaleza moral, estableciéndose en consecuencia una conexión necesaria entre derecho y moral. El mismo autor refiere cómo lo anterior genera varias consecuencias, de las cuales destacamos la referente al hecho de que la validez de las normas o de las decisiones "ya no depende de su mera existencia u origen social, sino de su adecuación formal y sustantiva a la Constitución y, más aún, de su consistencia práctica con ese horizonte de moralidad que preside y se recrea en la argumentación constitucional".

El surgimiento del neoconstitucionalismo o si se quiere del Estado constitucional, supone pues diferencias claras con el modelo anterior, que se ha dado en llamar Estado legislativo; estas diferencias se pueden observar, como lo dice Gloria Patricia Lopera (2004), a partir del análisis de los elementos característicos del Estado de derecho, huelga decir, reconocimiento de derechos, separación de poderes, principio de legalidad y control judicial, así:

a.- Reconocimiento de derechos: los derechos mantenían una relación de dependencia con la ley, de tal manera que su consagración legal se presentaba como condición necesaria para su reconocimiento, ejercicio y eficacia; en el Estado constitucional los derechos "cobran autonomía respecto de la ley y pasan a tener fundamentación constitucional, convirtiéndose así en parámetro de control de ley" (Lopera, 2004, p.24). Al respecto Uprimny, Rodríguez y García (2006, p. 299 y 300), manifiestan que anteriormente no se creía que la Constitución fuera una norma jurídica directamente aplicable en los casos concretos, sino un simple sistema de fuentes, situación que difiere de lo acontecido con el texto constitucional de 1991, en el cual se atribuye "una particular fuerza jurídica" a los derechos humanos, lo que implica la "vocación de aplicación judicial” del texto constitucional.

Retomando a Prieto Sanchís (2007), este autor diría que se incorpora el modelo de Constitución normativa, entendiendo por tal a aquella que "además de regular la organización del poder y las fuentes del derecho -que son dos aspectos de una misma realidad-, genera de modo directo derechos y obligaciones inmediatamente exigibles".

b.- Separación de poderes: entendiendo que en el esquema del Estado legislativo, de facto se presenta un estado de separación simplemente formal que impide el adecuado control recíproco de los órganos de poder; en el Estado constitucional se 
mira la forma clásica del sistema de "frenos y contrapesos", impidiendo la tradicional subordinación de las ramas del poder público a una de ellas.

c.- Principio de legalidad: identificado "con el imperio de la ley en el sistema de fuentes, su carácter vinculante para los demás poderes públicos y la reserva de ley como garantía de los Derechos de los ciudadanos" (Lopera, 2004, p.22). En el Estado constitucional se sustituye el tradicional "imperio de la ley" por la supremacía constitucional, la que lleva a: i) que la normatividad tenga que sujetarse a la Constitución, huelga decir, tanto en su proceso de producción como en su interpretación, la que, en consecuencia, se desarrolla mediante procedimientos de "interpretación conforme" y ii) que toda la normatividad tiene que desarrollar la Constitución. Robert Alexy diría: "La Constitución ya no es sólo base de autorización y marco del derecho ordinario. Con conceptos tales como los de dignidad, libertad e igualdad y el de Estado de Derecho, democracia y Estado social, la Constitución proporciona un contenido substancial al sistema jurídico" (Alexy, 2002, p.159).

Retomando una vez más a Prieto Sanchís, sobre este punto manifiesta que los operadores jurídicos ya no acceden a la Constitución a través del legislador, sino que lo hacen directamente, pues se presenta un fenómeno de "desbordamiento constitucional", que implica la inmersión de la Constitución dentro del ordenamiento jurídico y destaca que la remisión de los jueces a la Constitución se da de manera permanente, considerando que "es difícil encontrar un problema jurídico medianamente serio que carezca de alguna relevancia constitucional”.

c.- Control judicial: el que en desarrollo del Estado legislativo alcanza un opaco papel, limitado a ejercer: i) control sobre la actividad judicial, mediante el recurso de casación; ii) control sobre la actividad administrativa mediante la implantación de la jurisdicción de lo contencioso administrativo (Lopera, 2004, p.22), y; iii) control formal del proceso de producción legislativa, mediante la sala constitucional de la Corte Suprema de justicia. En el Estado constitucional, se mantienen las dos primeras formas de control judicial anteriormente comentadas, pero se sustituye el tercero, pues se elimina la sala constitucional de la Corte Suprema de Justicia y se da paso a la Corte Constitucional, la cual no se limita a examinar el proceso formal de la expedición normativa, sino que mira además que el contenido de los actos del legislador efectivamente desarrollen la Constitución. Mediante las labores de la Corte Constitucional se garantiza la supremacía constitucional (Younes, 1998, p.343).

Así entonces, el Estado constitucional no puede simplemente ser entendido como aquel en el que hay una Constitución vigente y una distribución de poderes, pues de ser así, todos los estados, o casi todos lo serían, sino que debe ser entendido como aquel en el cual el texto mismo de la Constitución y su aplicación, determinan 
Derecho ₹ Realidad

la forma en que ha de interpretarse y aplicarse el derecho, dada la existencia y reconocimiento de unos derechos fundamentales. "En este sentido, no cabe duda que el Estado constitucional representa una fórmula del Estado de derecho, acaso su más cabal realización, pues si la esencia del Estado de derecho es el sometimiento del poder al derecho, sólo cuando existe una verdadera Constitución ese sometimiento comprende también al legislativo; de ahí que quepa hablar del constitucionalismo como un perfeccionamiento del Estado de derecho". (Prieto, 2007, p. 104).

\section{Relaciones argumentación jurídica-neoconstitucionalismo}

La sujeción del Estado, su funcionamiento, los órganos de poder a esta nueva forma de entender el derecho, es decir, la sujeción del poder al derecho, requiere obviamente, una mayor y mejor justificación de las decisiones judiciales, (Atienza Rodríguez, 2006:17) pues en el esquema del neoconstitucionalismo, si bien el legislador mantiene un protagonismo fundamental, la última palabra se encomienda, irremediablemente, a los jueces (Prieto, 2007, p. 102).

Parafraseando a Mauricio Fioravanti (citado por Lopera, 2004, p. 13) el Estado constitucional ya no sería sólo el estado de la división de poderes y del gobierno limitado, sino que sería además el estado de los deberes del gobierno.

Por supuesto que si el ejercicio del poder se va a ver limitado por esa nueva forma de entender el derecho, se requiere que los jueces sustenten sus decisiones en razones plausibles, adecuadas, que puedan ser aceptadas no solo por las partes en conflicto, sino que además sean de buen recibo por la comunidad, y dentro de esta, especialmente por la comunidad jurídica (Perelman).

La antigua concepción del texto constitucional, en el cual se encontraba un sinnúmero de reglas formales que resultaban inconcluyentes o irrelevantes por su incapacidad de realización material, difiere entonces del nuevo esquema constitucional, que además de reglas incorpora el concepto de principios que permiten mediante adecuados procedimientos de discrecionalidad judicial, materializar el contenido constitucional y subyugar el ejercicio del poder frente al derecho. Esa rematerialización del texto constitucional es la base de la relación entre el neoconstitucionalismo y la argumentación jurídica, pues en el esquema anterior, la discrecionalidad sobre el desarrollo del texto constitucional, radicaba en cabeza del legislador, pero esa discrecionalidad correspondía a una discrecionalidad fundada, como máximo, en la legitimidad democrática del legislador, pero en manera alguna se presentaba como una discrecionalidad motivada o argumentada; en el actual esquema, la discrecionalidad se traslada a los jueces, pero a la manera de una discrecionalidad argumentada. 


\section{Grados de constitucionalización}

El fenómeno de la constitucionalización o del neoconstitucionalismo presenta diferentes grados de los que surgen a su vez diferentes problemas.

De un lado se tiene el fenómeno de la sobreconstitucionalización o supraconstitucionalización (Calderón, 2007, p.752), que es la figura que se presenta cuando la imposición de la Constitución como norma con vocación de aplicación judicial, tiene tal grado de aplicación que termina por despojar de relevancia jurídica la existencia de un orden normativo escalonado.

El otro extremo, corresponde al fenómeno de la infraconstitucionalización (Calderón, 2007, p.752), que se presenta cuando se reduce el valor normativo de la Constitución de tal manera que no se constituye sino en el marco que le dice al legislador como producir el derecho, en palabras de Prieto Sanchís, deja el texto constitucional como un "catecismo político o guía moral dirigida al legislador virtuoso" (Prieto, 2007, p. 107) y no más.

El punto intermedio entre estos extremos es aquel que en palabras de Robert Alexy, busca encontrar las condiciones de una constitucionalización adecuada, entendiendo por constitucionalización, en palabras de Alfonso García (citado por Calderón, 2007), “el proceso de transformación del derecho causado por la Constitución”. El camino para llegar a las condiciones pretendidas por Alexy, presenta la dificultad de no ser claro, no tiene un proceso predefinido, no hay fórmula mágica para el efecto, sino que se reduce al prudente arbitrio de los operadores jurídicos, arbitrio que no debe confundirse con lo que se ha dado en llamar un "Estado de justicia" (Aragón, 1997, p. 30 y 31) ${ }^{1}$, en el cual es el mismo operador jurídico quien decide cuando se acoge a la ley y cuando a la Constitución, pues esto, obviamente conllevaría a un grave estado de inseguridad jurídica.

\section{Argumentación jurídica y neoconstitucionalismo en Colombia}

Resulta indudable que con la expedición de la Carta Constitucional colombiana del año de 1991, nuestro país se ha matriculado en una forma de Estado Constitucional, dejando atrás el esquema de Estado legislativo. Las características diferenciadoras que citamos atrás, correspondientes a los elementos propios del estado de derecho, nos permiten dar suficiente respaldo a la anterior afirmación, pues hoy en día i) nadie puede negar que nuestra carta política es fuente primaria de reconocimiento de derechos con vocación de aplicación directa, es decir, aplicación que no requiere

Al emplear este término, el profesor Manuel Aragón Reyes sigue los planteamientos de Forsthoff. 
de previa consagración legal, sino que les basta su reconocimiento a nivel constitucional; ii) La separación de poderes, pareciera ser más clara, pues hoy es más fácil observar cómo nuestros jueces, especialmente los constitucionales, son más vigilantes de los procesos de producción legislativa y de ejercicio del poder. El constante "choque de trenes" entre el ejecutivo y el judicial, muestra como los controles recíprocos, aunque incómodos, están presentes; en fin, aunque en realidad falta garantizar más la independencia de las ramas del poder en nuestro país, de manera tal que se garantice el adecuado y cabal funcionamiento del sistema de "frenos y contrapesos", parece ser que se avanza firmemente en tal dirección; iii) Igualmente resulta evidente que en Colombia hoy en día todo el proceso de producción legislativa se sujeta a la Constitución, al igual que el proceso de interpretación, el que se ha ajustado a mecanismos de "interpretación conforme", lo que permite asegurar el desarrollo constitucional; iv) finalmente, se observa un mayor ejercicio en tareas de control judicial, lo que ha permitido que, con razón se afirme que "la justicia constitucional ha pasado a ser la instancia más visible de la justicia para el ciudadano corriente, y a través de fallos activistas tanto en control de constitucionalidad como en acciones de protección de derechos, ha pasado a ser un actor protagónico en la vida institucional del país. "(Uprimny, Rodríguez \& García, 2006, p. 299).

Así entonces, es claro que Colombia ha entrado de lleno a desarrollarse como estado constitucional, y en desarrollo de lo anterior, podemos incluso afirmar que ha asumido un esquema correspondiente a un "constitucionalismo fuerte", según las características que describen al mismo, en palabras de Prieto Sanchís (2007, p. 107), así:

.- Carácter normativo o fuerza vinculante de la Constitución.

.- Supremacía constitucional en el sistema de fuentes (artículo $4^{\circ}$ C.N.).

-- Eficacia o aplicación directa:

-- Garantía judicial.

.- Presencia de un denso contenido normativo destinado a los ciudadanos en sus relaciones de poder, contenido normativo conformado por reglas, principios, directrices, llamados a ser aplicados en casos concretos.

.- Rigidez constitucional. ${ }^{2}$

2 Esta sería, tal vez, la única falencia para que nuestro constitucionalismo sea catalogado realmente como fuerte, pues en casi 17 años, la Constitución colombiana ha sido reformada 26 veces, afectando a 64 artículos. Incluso, en palabras de Juan Manuel Charry, las reformas introducidas a la carta constitucional, habrían flexibilizado la misma. El mismo autor refiere que de continuar así "en pocos años nada quedará de la Constitución de 1991, sólo una colcha de retazos, sin técnica alguna, dictados por la ocasión política". (En AA.VV. Ámbito jurídico No. 244, 3 al 16 de marzo de 2008, pág. 14). 
Todo lo anterior supone que nuestro país, siendo ya un Estado constitucional, deba desarrollar adecuadamente, procesos argumentativos que permitan a los operadores jurídicos asumir el reto planteado por la discrecionalidad de que se les ha dotado.

La comprensión de la Constitución de 1991 como una Constitución de aplicación judicial directa, surge como consecuencia de la introducción a nuestro ordenamiento jurídico de conceptos tales como el de derechos fundamentales, entendidos estos como "la fase más avanzada del proceso de positivación de los derechos naturales en los textos constitucionales del Estado de derecho", como lo expresa Perez Luño (1998, p. 43 y 44), o como "Derechos humanos liberales del indivíduo", como los entiende Carl Schmitt (citado por Alexy, s.f., p. 24).

\section{Argumentación, constitucionalismo y derecho privado- derecho de los contratos}

Visto pues, como el Estado colombiano se ha matriculado como un Estado constitucional y lo que ello implica, es menester analizar el grado de constitucionalización que se está desarrollando en nuestro medio. Desde la perspectiva del derecho privado, pretendo demostrar como las actuaciones de nuestros jueces constitucionales nos adentran a una forma de supraconstitucionalización, acompañada además de una forma de "decisionismo", entendiendo por este último, en palabras de Manuel Atienza, el surgimiento de una serie de decisiones que no son convincentemente argumentadas (Atienza, 2006, p.64).

En materia de derecho privado, la constitucionalización ha sido inmensa. Sin analizar ahora los efectos que de ello ha derivado, podemos afirmar que instituciones tales como la familia han sufrido importantes modificaciones a través de diferentes sentencias de constitucionalidad de la normatividad civil y de tutela, al punto que no podría reconocerse la familia actual frente a la que originariamente regulaba el código civil colombiano. En efecto, la concepción de la familia ha sufrido transformaciones tan importantes que le han permitido erigirse como el núcleo esencial de la sociedad y elevar a canon constitucional la igualdad de sus miembros. Dichos cambios se han generado a partir de la evolución que han sufrido los conceptos de mujer, de hijos y de pareja. De manera extrema refiere Diana Saray Giraldo Mesa, que "Si el concepto de familia fuera el mismo, una pareja sin la bendición de la iglesia, sería ilegítima, un hijo nacido por fuera del matrimonio sería castigado por el mismo Estado y el adulterio de la mujer daría al marido, no sólo la facultad de quitarle sus hijos, sino también de enviarla a la cárcel por el tiempo que lo

estimara conveniente. Incluso si la ofensa a la hombría fuese corroborada "en el acto", podría matarla en defensa legítima del bien supremo de la honra”. (Giraldo, 2005) 
El régimen de propiedad privada, el ejercicio de algunas actividades de comercio como la banca, el mercado bursátil y asegurador entre otros, han sido también ampliamente modificadas. Sin embargo las modificaciones que se han introducido sobre tales instituciones, independientemente de cómo se han visto afectadas, resulta admisible si se considera que se trata de aquel tipo de instituciones que correspondiendo a la órbita del derecho privado, no se han mantenido en la esfera del ejercicio de la autonomía de la voluntad, sino que por el contrario han sido objeto de permanente control y regulación estatal.

No ocurre lo mismo con el "derecho de los contratos", pues en este campo se ha mantenido una regulación de tipo general que permite un amplísimo ejercicio de la autonomía de la voluntad, esto es, de la capacidad de los contratantes para definir por sí mismos los parámetros que han de regular sus relaciones en procura de la satisfacción de algunos tipos de necesidades. Lo anterior ha permitido tradicionalmente la consideración del contrato como fuente de derecho, más que como una realidad expuesta a fuentes de derecho, de esta manera se podría entender cómo, a manera de ejemplo, el artículo $4^{\circ}$ del Código de Comercio, establece que "Las estipulaciones de los contratos válidamente celebrados preferirán a las normas legales supletivas y a las costumbres mercantiles.", y más aún, se podría entender en una real dimensión lo dispuesto por el artículo 1603 del C.C., en cuanto el mismo confiere fuerza de ley al contrato.

Sin embargo de lo anterior, el contrato ha sido ya alcanzado por la larga sombra de la constitucionalización. El profesor Vincenzo Roppo (2005, p.19 y 20) comenta como en la escena italiana de las décadas de los años 70 del siglo XX, el contrato, en su interpretación, ejecución y desarrollo se vio ampliamente influenciado entre otros por el principio constitucional de la solidaridad, y se preguntaba si de dichos principios constitucionales podrían derivarse, directamente, causales de impugnación o invalidez de los acuerdos contractuales. Se discutía sobre los grados de amparo constitucional sobre los contratos, la forma de hacer efectivo dicho amparo y se discutía sobre la conveniencia de una tutela directa sobre los contratos o la conveniencia de una "tutela indirecta, filtrada por el médium de la protección constitucional de la iniciativa económica” (Roppo, 2005:20).

En el caso colombiano, la constitucionalización del derecho de los contratos, se ha dado tanto a través de sentencias de exequibilidad o como de fallos de tutela, afectando al contrato incluso desde i) su proceso de celebración y formación, ii) el alcance del concepto de la buena fe, y iii) ha llegado incluso a constitucionalizar las disputas contractuales surgidas entre particulares. Lo curioso de todo esto, es que la argumentación con la que la Corte Constitucional colombiana ha pretendido justificar sus decisiones, no siempre ha sido la más acertada y de ello deriva que no resulta ni convincente, ni satisfactoria para la comunidad jurídica. 
En palabras del profesor Jaime Alberto Arrubla Paucar (2006), la constitucionalización del derecho de los contratos, ha conllevado al incremento de la litigiosidad, con los graves efectos que se derivan para el problema de la congestión judicial y al desaliento de la inversión y del desarrollo económico, todo ello derivado de la inseguridad jurídica que se ha ocasionado.

i) Con respecto a la celebración y formación de los contratos, se hace claridad que tales actos encuentran su fundamento constitucional en los artículos 333 de la Constitución, en el que se lee que "La actividad económica y la iniciativa privada son libres, dentro de los límites del bien común. Para su ejercicio, nadie podrá exigir permisos previos ni requisitos, sin autorización de la ley”, y en el 16, correspondiente al libre desarrollo de la personalidad, en el que se lee que "Todas las personas tienen Derecho al libre desarrollo de su personalidad sin más limitaciones que las que imponen los Derechos de los demás y el orden jurídico."

De allí se desprende la libertad de los particulares para celebrar actos con consecuencias jurídicas o para no hacerlo, pues en principio, nadie está obligado a contratar. Allí se observa además, como la Constitución acoge la misma concepción liberal que inspira la normatividad civil, en la que se imponen los conceptos de buenas costumbres y orden público como límites al ejercicio de la autonomía privada.

Es claro entonces que no se puede esgrimir la libertad de contratación para efectos de violar derechos fundamentales. No se podría de esta manera, adelantar procesos o desarrollos contractuales que resulten discriminatorios, como por ejemplo lo ocurrido en Cartagena hace algunos años, cuando se pretendió impedir el ingreso de personas de color en algún tipo de establecimientos de comercio dedicados al ocio y a actividades festivas, bajo el pretexto de la libertad para no contratar con determinadas personas. Pero se desata el problema del concepto de lo que es discriminatorio cuando se habla de contratos de intuitu personae, como ocurre con los contratos bancarios, y allí cabe recordar lo acontecido, por ejemplo, con casos como el de la "Lista Clinton" (Corte Constitucional, sentencia SU-157, 1999).

La autonomía de la voluntad, permite entonces que las personas busquen las consecuencias jurídicas que quieran a través de los contratos con los únicos límites impuestos por las buenas costumbres y el orden público. El problema radica en tratar de establecer el contenido de las expresiones "orden público" y "buenas costumbres"; la jurisprudencia constitucional, lejos de contribuir a esclarecer estos conceptos, a contribuido a hacerlos más confusos, pues la ley 153 de 1887, había definido ya en su artículo 13, que la buena costumbre correspondía a la costumbre derivada de la moral cristiana, lo que de alguna manera permitía tener un referente, pero en análisis de constitucionalidad sobre esta norma, mediante sentencia C-224 de 1994, la Corte Constitucional declaró exequible la norma pero advirtiendo que 
la moral cristiana era la general hacia 1887 y que consecuentemente en esas épocas era un referente adecuado, hoy, bajo el concepto de pluralismo religioso, debe tenerse como referente a la moral general o la moral social, lo cual por indefinición, resulta totalmente inaplicable.

Situación similar ocurre con respecto al concepto de orden público. González Valencia refiere que el orden público son "todas aquellas disposiciones en que la sociedad está interesada y que miran al interés social y no al individual"; Valencia Zea dice que el orden público está representado por todos aquellos principios que constituyen las bases necesarias de nuestra vida social, así, lo único claro es que el concepto de orden público no está claro.

No resultando claros los conceptos anteriores, se tiene que no hay claridad tampoco para saber cómo y qué se puede o no contratar, es decir, no hay reglas claras para dirigir los procesos de contratación o de inversión.

En la sentencia SU 157 de 1999 se puede leer "La autonomía de la voluntad privada y, como consecuencia de ella, la libertad contractual gozan entonces de garantía constitucional. Sin embargo, como en múltiples providencias esta Corporación lo ha señalado, aquellas libertades están sometidas a condiciones y limites que le son impuestos, también constitucionalmente, por las exigencias propias del Estado social, el interés público y por el respeto de los derechos fundamentales de otras personas (...)". Entonces, a partir de esta sentencia y bajo la obligatoriedad del precedente judicial, surgen nuevos límites a la autonomía de la voluntad, determinados por, a) las exigencias propias del Estado social; b) Interés público y c) por el respeto de los derechos fundamentales de otras personas.

Bueno, y ¿qué es o cuáles son las exigencias propias del Estado social? En este punto volvemos a la indeterminación del concepto de buenas costumbres, es decir se ha fijado un nuevo límite, que resulta tan gaseoso como los anteriores. Se mantiene el interés público u orden público, con las dificultades interpretativas de este concepto ya vistas y se introduce el respeto a los derechos fundamentales de otras personas. En conclusión, la Honorable Corte no ha aclarado absolutamente nada y por el contrario ha añadido elementos gaseosos como determinantes del límite de la autonomía contractual.

ii) Alcance del concepto de buena $\mathrm{fe}^{3}$ : según el Código de Comercio, la buena fe debe estar presente desde el momento de celebrarse el contrato, pero debe mantenerse incluso durante la ejecución del mismo (artículo 871 C. de Co.); el Código Civil,

3 Este tema se tratará bajo los planteamientos expuestos por el profesor Jaime Alberto Arrubla Paucar en la conferencia antes citada. 
a su turno, refiere que la buena fe debe estar presente durante la ejecución del contrato (artículo 1603 C.C.), olvidando o dejando de lado tal concepto al momento de la celebración del acuerdo contractual.

Si el contrato se celebra de buena fe, no importa que el contrato sea de adhesión, implica que dicho contrato no puede conllevar cláusulas abusivas, de manera tal que al incluirse este tipo de cláusulas, se tendría que quien las incluye incurriría en incumplimiento al deber de buena fe. De allí se tiene entonces que el juez tendría herramientas suficientes para desechar las cláusulas abusivas de la contratación, y su deber de hacerlo, encontraría suficiente respaldo constitucional en el inciso tercero del artículo 13 constitucional, según el cual "El Estado protegerá especialmente a aquellas personas que por su condición económica, física o mental, se encuentren en circunstancia de debilidad manifiesta y sancionará los abusos o maltratos que contra ellas se cometan."

Así las cosas, es claro que ya la Constitución ha dado respaldo al concepto de buena fe y permite y a la vez, ordena al Estado, huelga decir a los órganos del poder público, defender a aquellas personas que se encuentren en estado de debilidad, situación que obviamente se presentaría en los contratos por adhesión. Nótese que el artículo constitucional en cita, manifiesta que es deber del Estado sancionar tal tipo de abusos, y es obvio que en materia de derecho civil o mercantil, tal acto de sanción sólo se da a través de la declaración de ineficacia o invalidez de los acuerdos contractuales.

De esta manera se estaría ya constitucionalizando la interpretación del contrato y no harían falta esfuerzos de constitucionalización judicial, pues de la simple interpretación normativa fluye este deber.

Pese a lo anterior, mediante sentencia C-068 de 1999, la H. Corte Constitucional, decidió pronunciarse sobre el alcance del principio de buena fe en materia contractual, cuando resolvió sobre la exequibilidad de los artículos 1852 del C.C., y 906 - 1 del Código de Comercio, referentes ellos a la prohibición de celebración de contratos de compraventa de bienes entre cónyuges no divorciados, prohibición esta que por mandato expreso del artículo $3^{\circ}$ de la Ley 28 de 1932 -también alcanzado por la sentencia- se hizo extensivo a todo negocio celebrado entre cónyuges que versara sobre bienes inmuebles, declarando inexequible la norma, bajo el argumento de que violaba el deber de buena fe.

En este punto, la constitucionalización judicial pretendida con el fallo atrás comentado, resulta forzada y mal fundada si se considera que la razón de ser de la medida prohibitiva, radicaba no en una supuesta mala fe de los cónyuges que se compravendían entre sí, o en el ánimo de defraudar a terceros, sino en la protección 
de la institución familiar, la estabilidad de la familia, considerando que ésta es el escenario de poder por excelencia a todo nivel, valga decir, afectivo, económico, social, etc., lo que de alguna manera impide una adecuada formación del consentimiento.

Debía considerarse que hacia la época en que se instituyó la norma, la representación legal de la mujer casada se radicaba en cabeza de su marido, lo cual hacía que en los contratos celebrados entre cónyuges, se realizara en realidad lo que se denominaba un "contrato consigo mismo", que impedía el acuerdo de voluntades como acto genitor del contrato.

Hoy en día, es cierto que ya el marido no tiene la representación de la mujer casada y que esto permitiría que efectivamente se formara el acuerdo de voluntades, pero ello no implica per se, que dicho acuerdo sea totalmente libre, pues las relaciones que se suscitan al interior del matrimonio, no permiten un adecuado nivel de discusión de las cláusulas contractuales, llevando incluso a poner en riesgo a la institución familiar. ${ }^{4}$ Como bien lo diría el magistrado Carlos Gaviria Díaz en el salvamento de voto a la sentencia C-068 de 1999, con la medida consignada en las normas demandadas, el legislador "se anticipa a pugnas disolventes e indeseables en el seno de la institución".

Así que se quiso, sin necesidad, extender el principio constitucional de la buena fe con una argumentación forzada, llegando al punto de trivializar el concepto, de manera tal que mereciera que el profesor Arrubla Paucar (2006) refiriera que si se reduce todo al principio de la buena fe, no habría razón de mantener, por ejemplo, el régimen de inhabilidades e incompatibilidades pues es obvio que estos presumirían la mala fe.

El tantas veces citado profesor Arrubla Paucar (2006), con razón ha referido que la falta de especialización del juez constitucional, le hace ignorante de la razón de ser de ciertas instituciones iusprivatistas llevándolo a conclusiones equivocadas.

iii) Constitucionalización de los debates contractuales entre particulares: Bien, la actualidad colombiana muestra como, principalmente a partir de la sentencia T222 del 2004, se inicia un fuerte proceso de constitucionalización del derecho de los contratos, principalmente en lo referente a los debates o litigios contractuales entre particulares. En efecto, dicha sentencia inicia por recordar cómo, en virtud de lo establecido por el artículo 86 de la Carta Política, la tutela procede en relaciones entre particulares en tres casos a saber: 1) Cuando se trata de particulares encargados

$4 \quad$ Respecto a estos argumentos, ver el salvamento de voto del Magistrado Vladimiro Naranjo Meza, a la sentencia C-068 de 1999. 
de la prestación de servicios públicos, 2) Cuando la conducta de los particulares afecte grave y directamente el interés colectivo, o 3 ) Cuando se trate de particulares respecto de quienes el solicitante de la tutela se halle en condiciones de indefensión o subordinación. Adicionalmente la Honorable Corte, recuerda que la procedencia de la tutela contra particulares tiene por objeto la adecuada restauración de situaciones de desigualdad que puedan presentarse en dichas relaciones.

La pregunta que surge de lo anterior, no podría ser otra más que aquella que trata de encontrar respuesta al interrogante de saber en cuál de los casos indicados por el referido artículo 86 de la carta política podría desarrollarse una acción de tutela surgida con ocasión de una disputa de carácter contractual.

La Sentencia T-222 del 2004, analiza la situación así descrita, de la siguiente manera:

-- Frente a la prestación de servicios públicos por parte de particulares, la H. Corte advierte que en estos casos no surgen excesivos problemas pues las condiciones de configuración del mismo parecen ser claras. En efecto, la jurisprudencia de la H. Corte Constitucional ha sido diáfana en determinar la procedencia de la tutela frente a particulares que prestan servicios públicos amen de reconocer que quien goza de una autorización del Estado para acceder a la prestación de un servicio público, goza a su vez de algunas prerrogativas propias de tal tipo de actividades, lo que consecuentemente obliga a dichos particulares a cumplir condiciones mínimas de derechos de los usuarios ${ }^{5}$. Así las cosas, la tutela frente a particulares que prestan servicios de comunicación, educación, salud, banca, etc., así se trate de conflictos de carácter contractual, resulta procedente como quiera que se trata de servicios públicos que han sido delegados a particulares. Una gran gama de servicios públicos, como los de acueducto, alcantarillado, aseo, energía eléctrica, distribución de gas combustible, telefonía fija y móvil, etc., han sido expresamente autorizados por la ley para ser prestado por particulares mediante la ley 142 de 1994, la que a su vez ha fijado el régimen de derechos y deberes que les corresponde observar tanto a los prestadores como a los usuarios de tales servicios.

-- Respecto de la afectación de un interés colectivo, la H. Corte ha referido que esta "no puede considerarse en abstracto más que en el sentido de que hipotéticamente es posible que una relación contractual conduzca a tal amenaza. Lo anterior, por la clara indeterminación constitucional de la hipótesis y las infinitas posibilidades de afectación de tales intereses" (Sentencia T-222 de 2004). En virtud de lo anterior, la corte evita pronunciarse respecto de esta posibilidad.

\footnotetext{
Entre otras, ver sentencia SU-157 de 1999. M. P. Alejandro Martínez Caballero.
} 
Derecho \& Realidad

.- Así las cosas, resta mirar la última de las hipótesis consignadas en el artículo 86 , correspondiente a los casos de subordinación y de indefensión, sobre los cuales la Corte ha considerado que la facultad de tutelar en contra de particulares por esta causal "tiene su fundamento jurídico en el derecho de igualdad, toda vez que quien se encuentra en alguna de las situaciones referidas no cuenta con las mismas posibilidades de defensa que otro particular. " (Corte Constitucional, sentencia C134, 1994)

Visto lo anterior, se hace necesario recordar cómo es que la $\mathrm{H}$. Corte entiende los conceptos de subordinación y de indefensión, para lo cual debemos remitirnos a la sentencia T-290 de 1993, en la cual la alta corporación refiere que la subordinación alude a la existencia de una relación jurídica de dependencia, como ocurre, por ejemplo, con los trabajadores respecto de sus patronos, en tanto que la indefensión, si bien hace referencia a una relación que también implica la dependencia de una persona respecto de otra, ella no tiene su origen en la obligatoriedad derivada de un orden jurídico o social determinado sino en situaciones de naturaleza fáctica en cuya virtud la persona afectada en su Derecho carece de defensa, entendida ésta como posibilidad de respuesta efectiva ante la violación o amenaza de que se trate. (Sentencia T-290, 1993)

Así entendidos estos conceptos y ya en materia de constitucionalización de debates contractuales de derecho privado, es claro que no se enmarcan en casos de subordinación, pues la desigualdad en este tipo de controversias (controversias contractuales de derecho privado), corresponde a una forma de desigualdad funcional diferente a lo ocurrido en materia de derecho laboral, en donde las diferencias generan una forma de desigualdad negocial que las hace más propensas a la tutela constitucional.

Entonces solo nos quedaría mirar la situación correspondiente a estados de indefensión, de los que la alta corporación ha manifestado que desde una perspectiva exclusivamente jurídica, quien celebra un contrato, se sujeta al mismo de tal manera que resulta obligada por los términos de su acuerdo y así afirma que en tales condiciones, quien ha contratado corre "una suerte de situación de indefensión".

Tal indefensión, dice la corte, es el resultado de dos elementos diferentes, i) la seriedad con que ha de tomarse el principio pacta sunt servanda, que impide que uno de los contratantes de manera autónoma y arbitraria, deje de cumplir con lo pactado, y ii) que la persona queda en situación de indefensión bajo la consideración de que su contraparte tiene la posibilidad de demandar el cumplimiento de lo pactado, concluyendo entonces que se presenta una tensión para esta persona entre su derecho al buen nombre y otros derechos fundamentales. Se generaría aquí, en el sentir de la corte constitucional, un presunto dilema jurídico, pues si el contratante incumple 
lo pactado para proteger sus derechos fundamentales, se verá afectado su buen nombre y si protege su buen nombre, se verá en la situación de que sus derechos fundamentales terminen afectados.

-- Con respecto a los casos en los cuales procedería la acción de tutela, refiere que deben analizarse dos situaciones en abstracto refiriéndose inicialmente al caso en que se presenten contratos o relaciones jurídicas con objeto incompatible con la Constitución, de esta manera aquellos contratos fundados en procesos discriminatorios o contentivos de cláusulas violatorias de derechos fundamentales serían claramente viables de ser intervenidos por el juez constitucional a efectos de controlar tales actuaciones contrarias a la Constitución.

De otro lado se refiere a aquellos casos en que los efectos de inconstitucionalidad no devienen del contrato en sí mismo sino de su cumplimiento, es decir, contratos en los que el contenido resulta ajustado al texto constitucional pero que la ejecución del acuerdo contractual conduce a consecuencias contrarias a los principios constitucionales.

A partir de lo anterior, surgen las diferentes posibilidades de acción en defensa de la supremacía constitucional, las que se reducen a cuatro, así:

a.- La defensa de la supremacía por parte de los jueces ordinarios, quienes tienen la obligación de considerar en los asuntos sometidos a su conocimiento, las cuestiones de orden constitucional que se puedan presentar. Dicho de otra manera, corresponde a la obligación de los jueces ordinarios de examinar la incidencia de la Constitución y de los derechos fundamentales en el debate contractual de que estén conociendo. (Sistema primario).

b.- La procedencia de la acción de tutela cuando resulte evidente la violación de derechos fundamentales y confluyan los presupuestos procesales para el efecto. (Acción de tutela).

c.- La procedencia de la acción de tutela pero esta vez por la existencia de una vía de hecho judicial, cuando concurran los presupuestos fácticos y procesales requeridos para el efecto, derivados de la omisión al sistema primario ya referido, y

d.- Un sistema abstracto de control constitucional sobre la normatividad general referente al denominado "derecho de los contratos".

Todo lo arriba expuesto, carece sin embargo de la argumentación adecuada para efectos de justificar suficientemente la constitucionalización pretendida del derecho de los contratos, si se tiene en cuenta el análisis de los siguientes argumentos: 
1.- El argumento según el cual quien celebra un contrato, se sujeta al mismo de tal manera que resulta obligada por los términos de su acuerdo y consecuentemente, quien ha contratado corre "una suerte de situación de indefensión". Este razonamiento no resiste las modernas concepciones que alrededor del cumplimiento - incumplimiento de los contratos realizan los más autorizados exponentes de esta rama del derecho. En efecto, el profesor italiano Vincenzo Roppo, comenta como a partir de la moderna escuela del análisis económico del derecho de origen norteamericano, se estima que del contrato no surgen obligaciones de cumplimiento del contrato, sino poderes de elección entre cumplimiento e incumplimiento/resarcimiento, que se reducen a análisis de pura conveniencia económica (Roppo, 2005: 18 y 87). Alrededor de este tipo de análisis se sumarían importantes principios del derecho contractual, como aquellos que propugnan por cargas de conocimiento, de sagacidad, de legalidad y de claridad de parte de los contratantes, que orientarían a la imposición de cláusulas como las de adictio in diem, o las que imponen arras de retractación, entre otras, que permitirían una mejor opción entre las posibilidades de cumplimiento - incumplimiento.

2.- Ahora bien, frente a la posibilidad de acceder a una forma de constitucionalización de los debates contractuales cuando los acuerdos entre particulares involucren alguna forma de violación a derechos fundamentales, bastaría con considerar que los derechos fundamentales han sido considerados como derechos personalísimos ${ }^{6}$ y por tanto indisponibles en materia contractual, y que consecuentemente la consagración de algún tipo de cláusula contractual que atente en contra de los mismos generaría la nulidad del acuerdo por la presencia de objeto ilícito a la luz de lo dispuesto por el artículo 1521 del C.C. De esta manera se podría lograr la inejecución del contrato atentatorio de los derechos fundamentales sin necesidad de constitucionalizar el conflicto contractual, esto es, manteniéndolo dentro de la órbita de la jurisdicción ordinaria y por las vías del derecho civil o mercantil.

3.- En términos generales se podría decir que los argumentos en los que se ha pretendido sustentar la necesidad y la bondad de la constitucionalización del derecho de los contratos, corresponde a motivaciones inadecuadas que llevan a una clara forma de "decisionismo" ajeno por entero a los parámetros de seguridad y plausibilidad derivados de la teoría de la argumentación jurídica.

En la sentencia T-769 de 2005, que resuelve un caso de un litigio contractual acaecido en nuestra ciudad, se puede observar con claridad meridiana un argumento que por lo forzado de su contenido no mereciera comentario alguno. Dicha sentencia se produce dentro del marco fáctico que de manera sucinta se expone a continuación: En el mes de noviembre de 2002, ocurrió un incendio en el centro comercial la 17, que destruyó buena parte de sus tiendas y la mercancía que había en ellas.

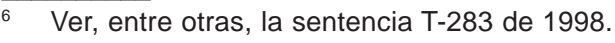


Los actores resaltan que del trabajo que ejercían en cada uno de los almacenes derivaban el único sustento para vivir y señalan que al término de la restauración del edificio se acercaron a la oficina de la administradora, quien les indicó que el canon mensual de arrendamiento de los locales fluctuaba entre un millón y un millón trescientos mil pesos, lo que constituye un aumento del 100 o 150 por ciento en el valor de la renta en comparación al antiguo monto del alquiler. También destacan que se añadieron varios requisitos para celebrar el contrato respectivo. Observan que ante el aumento del canon y de los requisitos para arrendar un local, se remitieron a la casa de la justicia y la personería municipal de Pasto; esta última citó al representante legal de la sociedad "Inmuebles y Arrendamientos Ltda", pero este no se presentó a ninguno de los requerimientos.

Ante lo anterior, aducen encontrarse en situación de indefensión frente a la arrendadora quien desde antes de producirse el incendio imponía su voluntad debido al "estado de necesidad" en el que se encuentran.

Por todo lo anterior, solicitan se ordene a los accionados reconocer el derecho de preferencia contenido en el artículo 521 del Código de Comercio y asignar un local del Centro Comercial La 17 de la ciudad de Pasto. También requieren se ordene una indemnización en abstracto conforme al artículo 25 del Decreto 2591 de 1991.

Frente a los hechos así expuestos, la Corte Constitucional hace, entre otras, la siguiente afirmación: "Al contrario de lo establecido en el numeral 1 del artículo 2008 del Código Civil, la destrucción de la cosa arrendada, en este caso el inmueble en donde se encuentra un establecimiento de comercio, no expira el arrendamiento, sino que permite al arrendador dar por terminado el contrato siempre que-se repite-desahucie a los arrendatarios en los términos indicados. Por tanto, si no existe desahucio se entiende que el contrato prosigue y, en consecuencia, las diferencias que surjan como consecuencia de la renovación, pueden solucionarse por un juez sin que se desaloje a los comerciantes o se les impida realizar su labor u oficio. (Subraya fuera de texto).

Lo anterior, además, sin perjuicio del tercer y cuarto beneficio consignado en el legislación comercial para el arrendatario de un local comercial: (i) el Derecho de preferencia de los anteriores arrendatarios (artículo 521 del Código de Comercio) cuando quiera que se extinga la relación contractual conforme al artículo 520, y (ii) la indemnización de perjuicios a favor del empresario (artículo 522 ejusdem)".

Bien, la H. Corte, desconoce que la terminación del contrato de arrendamiento ocurrió por sustracción de materia, habida cuenta de la ocurrencia del siniestro que destruyó el inmueble arrendado y que tal terminación no ocurrió por labores derivadas de remodelación o reconstrucción que voluntariamente realizara el propietario, 
presupuestos estos necesarios para la procedencia y aplicación del artículo 521 del Código de Comercio, esgrimido por la alta corporación y que se refiere al derecho de preferencia. Desconoce igualmente que la destrucción de la cosa arrendada a que se refiere el artículo 2008 del C.C. sí es aplicable en materia mercantil, en virtud de la remisión que de manera expresa hacen hacia tal normatividad los artículos $2^{\circ}$ y 822 del Código de Comercio.

Pero lo más grave es que exige que, pese a la ocurrencia del siniestro y consecuentemente a la destrucción del inmueble arrendado, la terminación del contrato debe estar antecedida del respectivo desahucio... (i?), so pena de considerar que al no realizarse el desahucio, el contrato prosigue, lo que debe entenderse que continúan las obligaciones tanto del arrendador, -que en el presente caso sería permitir el uso de un bien que ya no existe-, como del arrendatario -que correspondería a pagar un canon mensual por un bien que ya no puede disfrutar-.

El último caso planteado tuteló efectivamente los derechos de los actores, fundándose tal pronunciamiento en el principio de la solidaridad, lo que de alguna manera coincidiría con lo expuesto en el caso de la constitucionalización del derecho de los contratos en el caso italiano comentado líneas arriba.

Como se puede ver, la constitucionalización del derecho de los contratos se ha presentado de una manera tan fuerte, ha sido tan agresiva, que incluso se ha descuidado el deber argumentativo y se ha roto la relación necesaria entre la argumentación jurídica y constitucionalismo que atrás comentamos. De esta manera el principio pacta sunt Servanda, garante de la seguridad jurídica y de los efectos vinculantes de los contratos, que solo sucumbía ante el principio rebuc sic stantibus, siempre que se presentasen las condiciones de imprevisibilidad de los hechos y el grave desequilibrio económico en contratos conmutativos, ahora sucumbe también ante los efectos derivados de la discrecionalidad judicial acompañada de una indebida argumentación de las justificaciones de los fallos de los operadores jurídicos.

Se ha olvidado que la constitucionalización es un proceso, no una cualidad de todo o nada, algo que se tiene o no se tiene, como bien lo advierte Guastini (citado por Prieto, 2007, p. 106), cuando este comenta el caso italiano. En el mismo sentido se pronuncia el profesor Paolo Comanducci (citado por Calderón, 2007, p.752), quien señala que la constitucionalización del derecho debe ser progresiva, es un proceso en el cual el derecho termina siendo impregnado por la Constitución, recordando además que se trata de un proceso graduado, de manera tal que un derecho puede ser más o menos constitucionalizado.

En el afán de constitucionalizar el derecho y especialmente el derecho de los contratos, se estaría presentando pues un fenómeno de supraconstitucionalización, entendido 
este, como lo indicamos líneas arriba, como el estado aquel en que la imposición de la Constitución como norma con vocación de aplicación judicial, tiene tal grado de aplicación que termina por despojar de relevancia jurídica la existencia de un orden normativo escalonado.

En efecto, la vocación de aplicación de la Constitución habría terminado por abordar problemas que perfectamente podían y pueden aún, ser debidamente tratados por las disposiciones legales, limitándose el proceso de verificación de la supremacía constitucional a desarrollar el proceso abstracto de control sobre la normatividad general referente al denominado "derecho de los contratos".

Conviene aquí recordar las palabras del profesor Manuel Aragón Reyes (1997, p.37), cuando ha manifestado:

Ahora bien, que la Constitución desplace a la ley de manera que problemas de arrendamientos urbanos, de operaciones bancarias, de disciplina urbanística, de contratación laboral, de seguridad social, de contratación administrativa, etc., hayan de resolverse aplicando la Constitución, como si esta fuese la única disposición normativa de nuestra Nación y en ella se contuviesen las reglas resolutorias de todos los conflictos, parece, cuanto menos, improcedente.

Frente a esa tendencia (real, aunque por fortuna aún no mayoritaria en la doctrina y en los aplicadores del Derecho) hay que afirmar enérgicamente, que la ley sigue siendo, sobre todo en un Estado democrático, la expresión más ordinaria del Derecho (esto es, la decisión normadora producto, en cada momento, del juego legítimo del pluralismo político); que la Constitución ha dejado (en mayor o menor grado, según la materia) un margen de discrecionalidad al legislador que los juristas (incluyendo a los jueces, claro está) han de respetar; que solo cuando no existe ley para el caso pueden los jueces aplicar directamente la Constitución".

\section{Y finalmente, hacia dónde vamos?}

Vale recordar que líneas atrás comentamos como el proceso de la constitucionalización del derecho de los contratos, encuentra como referente el caso italiano ocurrido en la década del setenta del siglo XX. También es necesario recordar que tal fenómeno de constitucionalización se dio en medio de un proceso de constitucionalización general del derecho italiano, en la escuela del uso alternativo del derecho, encabezado por el movimiento progresista denominado la "Magistratura Democrática Italiana", la que impulsaba una visión de un juez activista, que ocupaba el lugar de un actor político y que no se limitaba ya a ser la voz de la ley. 
Buscaba este movimiento que el derecho sea empleado como un elemento emancipador y transformador, y planteaba, a través de Luigi Ferrajoli, uno de los principales exponentes de este movimiento, que de las diversas interpretaciones que permite la ley, la elección debía hacerse no a través de elementos netamente jurídicos sino metajurídicos, como serían las consideraciones de tipo político. Se impulsó el concepto de supremacía de los principios constitucionales, y se estableció una metodología que buscaba "formar e informar" a la comunidad mediante novedosos sistemas de publicidad.

Sin embargo, en 1977 se vislumbraron los primeros síntomas de crisis del movimiento, crisis que entre otras causas, encontró su origen en el desmesurado protagonismo del sector judicial, implicado en un considerable aumento de su espacio de discrecionalidad, con una cierta instrumentalización política del mismo, que empezó a demostrarse de cierta forma incontrolable y altamente lesivo y nocivo para determinados valores jurídico - democráticos, como fue el caso de los derechos y garantías fundamentales de los ciudadanos”. (Souza, 2001, p.169).

Lo anterior degeneró en la consideración de algunos sectores internos de la Magistratura de que dicho protagonismo judicial, tan importante en otras épocas, resultaba siendo un peligro para la legalidad, para la seguridad jurídica y para el sistema de garantías democráticas. Algunos de los miembros de la Magistratura Democrática abogaban pues, por el regreso a algunos de los valores formales como la certeza del derecho, la previsibilidad de las decisiones judiciales y la vinculación del juez a la ley.

Lo anterior explicaría entonces, por qué en el caso italiano el fenómeno de la constitucionalización del derecho de los contratos tuvo una corta vida, o fue una estación breve, como lo diría el profesor Vincenzo Roppo, quien añade que "Pasados los años 70 y los primeros años de los 80 , aquella clase de jurisprudencia comenzaba a ser una rareza para después desaparecer" (Roppo, 2005, p.20).

Finalmente agrega el profesor italiano en cita, que ya hoy en día, "se encuentra visiblemente mermado -inclusive en la doctrina- el empeño por tener a las normas constitucionales como fuente del derecho contractual, bien en su sentido primario, como criterio de legitimidad de las leyes, o bien en su posible papel de regla susceptible de aplicación directa a las reglas contractuales litigiosas" (Roppo, 2005, p.20).

Obviamente existen diferencias sustanciales en las condiciones sociopolíticas en las que se desarrollan los esquemas activistas y de constitucionalización del derecho tanto italiano como colombiano, de manera tal que no podríamos aventurarnos a afirmar un desenlace del activismo colombiano similar al ocurrido en el caso italiano. Pero tampoco podríamos afirmar que el activismo de nuestros jueces y en general de nuestro sistema judicial, se encuentre inmune a un fenómeno de desbordamiento del protagonismo judicial. 


\section{Referencias}

Alexy, R. (2002). El concepto y la validez del derecho. Barcelona: Gedisa.

Aragón, M. (1997). El juez ordinario entre legalidad y constitucionalidad. Bogotá: Instituto de Estudios Constitucionales Carlos Restrepo Piedrahíta, Universidad Externado de Colombia.

Atienza, M. (2006). El derecho como argumentación. Barcelona: Ariel.

Bonorino, P. R. \& Peña, J. I. (s.f.). Argumentación judicial: construcción, reconstrucción y evaluación de argumentaciones orales y escritas. S.1.: Plan Nacional de Formación y Capacitación de la Rama Judicial.

Calderón, J. J. (2007). La constitucionalización de las controversias contractuales. En AA. VV. Los contratos en el derecho privado. Bogotá: Legis.

Corte Constitucional. (1993). Sentencia T-290.

Corte Constitucional. (1994). Sentencia T-134.

Corte Constitucional. (1994). Sentencia C-224.

Corte Constitucional. (1998). Sentencia T-283.

Corte Constitucional. (1999). Sentencia C-068.

Corte Constitucional. (1999). Sentencia SU-157.

Corte Constitucional. (2004). Sentencia T-222.

Corte Constitucional. (2005). Sentencia T-769.

García, J. A. (2006). ¿Existe discrecionalidad en la decisión judicial? O de cómo en la actual teoría del Derecho (casi) nada es lo que parece y (casi) nadie está donde dice. Conferencia pronunciada en el II Congreso nacional y I Internacional de Derecho Constitucional. Universidad de Nariño, San Juan de Pasto.

García, J. A. (1999). Escritos sobre filosofía del derecho. (1a ed.). Bogotá: Ediciones Rosaristas.

Lopera, G. P. (2004, marzo). La aplicación del derecho en los sistemas jurídicos constitucionalizados. Cuadernos de investigación Universidad Eafit.

Marrero, D. (2006, junio-julio). Normas y descripciones: diferentes perspectivas de la teoría de la argumentación jurídica. Revista Pensamiento Jurídico, (16).

Pérez, A. E. (1998). Los derechos fundamentales. Madrid: Tecnos.

Prieto, L. (2007). Sobre el neoconstitucionalismo y sus implicaciones. Revista Ámbito Jurídico, (23). 
Roppo, V. (2005). El contrato del dos mil. Bogotá: Universidad Externado de Colombia.

Uprimny, R., Rodríguez, C. \& García, M. (2006). Justicia, democracia y violencia en Colombia: La evolución del sistema judicial en las últimas dos décadas. En ¿Justicia para todos? Sistema judicial, derechos sociales y democracia en Colombia. Bogotá: Norma.

Weston, A. (2005). Las claves de la argumentación. Barcelona: Ariel.

Younes, D. (1998). Derecho constitucional colombiano. Bogotá: Legis. 